\title{
Glass: Home of the Periodic Table
}

\author{
Georgiy Shakhgildyan*, Alexey Lipatiev, Sergey Lotarev, Sergey Fedotov and \\ Vladimir Sigaev
}

Department of Glass and Glass-Ceramics, Mendeleev University, Moscow, Russia

Glass is the most common material around us, and humankind uses it every day for more than 5000 years. However, from the chemical point of view, glass is the only material that could represent almost all elements of the Periodic Table inside itself, showing the effect of the Periodic Law on properties of the final material. In this paper, we show the most remarkable examples demonstrating that glass can rightfully be called "home" for all chemical elements providing different properties depending on its composition. We gave a new look at the Periodic Table and described how a small number of glass-forming components creates unique glass structure which could enclose almost all remaining elements including transition and noble metals, lanthanides and actinides as modifying components providing an inconceivable number of discoveries in material science. Moreover, we reviewed a series of studies on the direct femtosecond laser writing in glasses which paves the way for a redistribution of chemical elements in the spatially confined nanosized zone in glass volume providing unique properties of laser-induced structures. Finally, for the first time, we reproduce the Periodic Table in birefringence colors in the bulk of silica glass using a direct laser writing technique. This image of 3.6 $\times 2.4 \mathrm{~mm}$ size can withstand temperature up to $900^{\circ} \mathrm{C}$, humidity, electromagnetic fields, powerful cosmic and reactor radiation and other environmental factors and demonstrates both the art of direct laser writing and symbolic role of glass as the safest and eternal home for the Periodic Table.

Keywords: Periodic Table, glass, glass-ceramics, glass formation, direct laser writing

Peter the Great St.Petersburg

Polytechnic University, Russia

*Correspondence:

Georgiy Shakhgildyan georgiy.shahgildyan@gmail.com

Specialty section:

This article was submitted to Inorganic Chemistry,

a section of the journal

Frontiers in Chemistry

Received: 15 March 2020 Accepted: 14 April 2020 Published: 30 April 2020

Citation:

Shakhgildyan G, Lipatiev A, Lotarev S, Fedotov S and Sigaev V (2020) Glass: Home of the Periodic Table.

Front. Chem. 8:384.

doi: 10.3389/fchem.2020.00384

\section{INTRODUCTION}

Glass has been known to mankind for more than 5000 years, and it is one of the most common materials in modern life. Despite its long history, glass remains one of the most interesting objects to study in the field of inorganic materials science. Thanks to the work of researchers around the world and the variety of chemical elements collected in the Periodic Table, new glass compositions and processing methods are produced every year, creating new materials for the development of vital and sustainable technologies. According to theoretical calculations, the number of possible compositions of glasses is so large that the synthesis of all compositions would require the number of atoms close to the maximum theoretical content of atoms in the whole Universe (Zanotto and Coutinho, 2004). Understanding the importance of glass science and technology, D. I. Mendeleev himself was actively engaged in the development of new glass-based materials, his main results were reflected in his 1864s book "Glass Production" (Mendeleev, 1864).

In this paper, in honor of the recent anniversary of the Periodic Table of chemical elements, we briefly describe how a large class of glasses can be classified into groups of chemical elements of the Periodic Table and give a look on the perspective developments in the field of glass which make it one of the most promising materials of our time. 


\section{GLASS FAMILIES AND THEIR PLACE IN THE PERIODIC TABLE}

As mentioned above, almost all elements of the Periodic Table can be used for the production of glass, which makes it a kind of "home" for all elements. Depending on the type of chemical compounds that form glasses, they are divided into classes, each of which has a unique structure and properties that determine their application.

The most common class of glasses is oxide glasses. They are formed by structural units that are compounds of various elements with oxygen. These elements primarily include $\mathrm{Si}, \mathrm{Ge}$, B, P, As, their oxides are easily obtained in a glassy state and most glasses are produced on their basis. Also, oxides of Te, Ti, Se, $\mathrm{Sb}, \mathrm{Mo}, \mathrm{W}, \mathrm{Bi}, \mathrm{Al}, \mathrm{Ga}, \mathrm{V}$, and other elements can act as glassforming agents, either individually or in a mixture with other oxides. Depending on the type of the main glass-forming oxide, the name of the group of glasses is derived-silicate, phosphate, tellurite, etc.

A special place among oxide glasses is occupied by fused silica or silica glass $\left(\mathrm{SiO}_{2}\right)$. It is the most refractory glass, it has a wide transparency window in the optical region and an abnormally low coefficient of thermal expansion (CTE) equal to $5.5 \cdot 10^{-7} / \mathrm{K}^{-1}$ (LeLosq et al., 2019). These determine its wide range of applications-from UV lamps to optical elements. It is thanks to the development of silica glass technology and the production of optical fibers that the worldwide implementation of broadband Internet access has become possible (Ballato and Dragic, 2016).

Silicate glasses which include oxides of various chemical elements from groups 1 to 17 are the most extensive group of glasses. In addition to $\mathrm{Si}$ and $\mathrm{O}$, the most important elements of silicate glasses are alkaline ( $\mathrm{Li}, \mathrm{Na}, \mathrm{K})$ and alkaline earth ( $\mathrm{Mg}, \mathrm{Ca}, \mathrm{Sr}, \mathrm{Ba})$ metals, as well as elements $\mathrm{Al}$ and $\mathrm{B}$. Due to high transparency, acceptable strength and relatively low cost of production, products made of silicate glasses are present in all areas of human life: construction and transport, storage of products, machinery and much more. Ion exchange technology which includes replacement of small metal ions with larger ones in the surface layer of silicate glasses allows to significantly increase glass strength, which is used to create flexible mobile devices (Mauro and Morten, 2016). Using silicate glasses and different thin-film layers smart glasses are developed. Smart glass technology enables the fabrication of glass-based devices to control passing light. This can considerably decrease the building's energy demands with improving the indoor environment (Rezaei et al., 2017). The introduction of various chemical elements into the glass composition (mainly transition, rare earth, and noble metals), leads to the coloring of glasses. Even elements of the actinide group can be used for the production of glasses. Thus, $\mathrm{U}_{2} \mathrm{O}_{3}$ has long been used for the production of tableware, jewelry and optical filters, since $U$ ions give a bright green color to the glass (Strahan, 2001). Currently, the ability of silicate glasses to contain radioactive elements ( $U$, $\mathrm{Pu}$ ) is used for the disposal of radioactive waste in vitrification technology (Gin et al., 2013). If it is necessary, some elements can be even converted to a radioactive state in glasses, thereby creating radiopharmaceuticals. Thus, glass microspheres with the $\mathrm{Y}^{90}$ isotope for liver cancer treatment are produced using $\mathrm{Y}_{2} \mathrm{O}_{3}-\mathrm{Al}_{2} \mathrm{O}_{3}-\mathrm{SiO}_{2}$ glass (Ehrhardt and Day, 1987; Sigaev et al., 2012). Moreover, utilizing silicate glasses containing oxides of $\mathrm{Al}, \mathrm{Li}, \mathrm{Mg}, \mathrm{Ca}, \mathrm{Ti}, \mathrm{Zr}, \mathrm{P}$, and other elements, glass-ceramics can be made by the bulk nucleated crystallization routine. Glassceramics demonstrate different combinations of properties [high strength, zero porosity, precision-regulated coefficient of thermal expansion (CTE), including near-zero values, biocompatibility, etc.] and find applications in various fields from medicine to astronomy (Zanotto, 2010).

The industrial production of non-silica oxide glasses is less widespread. Meanwhile, new challenges in science and technology lead to the development of such glasses. $\mathrm{TeO}_{2}$-based glasses have an increased refractive index $(>2.0)$ and are used in complex optical devices in the visible and near-IR range. $\mathrm{GeO}_{2}$-based glasses are actively being studied to create new optical and laser components (Sigaev et al., 2011; Starobor et al., 2016). Borate glasses (based on $\mathrm{B}_{2} \mathrm{O}_{3}$ ) with additives of different oxides are used in medicine for the restoration of soft tissues, in optics and photonics (Lorenzi et al., 2018; Feller, 2019). Phosphate glasses (based on $\mathrm{P}_{2} \mathrm{O}_{5}$ ) containing oxides of rare earth elements $(\mathrm{Nd}, \mathrm{Eu}, \mathrm{Tb}, \mathrm{Er}, \mathrm{Yb})$ are used in industry for the production of active elements of high-power lasers (Campbell and Suratwala, 2000). Phosphate and borate glasses with additives of $\mathrm{Zn}, \mathrm{Sn}, \mathrm{B}, \mathrm{Al}, \mathrm{Na}, \mathrm{K}$ oxides are widely used for: sealing materials with a variety of CTE values, biomedical applications and the development of solid electrolytes for the new generation of batteries (Muñoz et al., 2019).

Glasses formed by the elements of group 16 (S, Se, Te) together with elements of group 14 and 15 (Ge, Sn, P, As, Sb) belong to the class of chalcogenide glasses. These glasses have ultrahigh transparency in the IR range (up to 25 microns), which determines their use as IR imaging devices in new generation thermal imagers, optical sensors for IR spectroscopy and active elements of fiber $\mathrm{CO}_{2}$ lasers (Hubert et al., 2011).

The class of halide glasses includes materials based on elements of group 17 (primarily $\mathrm{F}$, also $\mathrm{Cl}, \mathrm{Br}, \mathrm{I}$ ) in the combination with metals ( $\mathrm{Be}, \mathrm{Zr}, \mathrm{Hf}, \mathrm{Ba}, \mathrm{La}, \mathrm{Al}, \mathrm{Y}$ ). The most widely studied glass composition is ZBLAN (in the $\mathrm{ZrF}_{4}-\mathrm{BaF}_{2}-\mathrm{LaF}_{3}-\mathrm{AlF}_{3}-\mathrm{NaF}$ system). Production of such glasses is complicated by their high tendency to crystallization and extremely high requirements for the degree of purity of raw materials. However, research in this area is justified by the possibility of obtaining optical fibers with minimal optical losses which could provide a significant (up to 100 times) increase in data transfer speed compared to current fiber cables and open the way for a new generation of near-IR fiber lasers (Wetenkamp et al., 1992; Clare et al., 2019). It is worth noting that the researchers have established the possibility of obtaining a defectfree fiber from ZBLAN glass in the absence of gravity and are currently conducting experiments to obtain such a fiber on the International space station (Starodubov et al., 2014).

Metal glasses are the general name of a wide class of amorphous materials consisting of metals or alloys of metals and metalloids, including elements of groups 2-15 (the most common are $\mathrm{Zr}, \mathrm{Ti}, \mathrm{Cu}, \mathrm{Ni}, \mathrm{Be}, \mathrm{Mg}, \mathrm{Fe}, \mathrm{Co}$, etc.). Metal glasses have high crystallization tendency which could be overcome by unusually high melt cooling rates (from $10^{5}$ to $10^{12}{ }^{\circ} \mathrm{C} / \mathrm{s}$ ). The 
advantages of metal glasses over metals and metal alloys are high values of mechanical strength, corrosion resistance, magnetic properties and electrical resistance. Currently, it is possible to produce not only metal glasses in the form of thin plates but bulk products with complex surface morphology (Greer, 1995; Schroers, 2013).

Thus, almost all elements of the Periodic Table in various ratios and compounds can be part of the glass, changing its structure and giving unique properties to the material. The abundance of variations in the composition and methods of glass production opens up new directions for its use in the promising fields of optics, medicine, photonics, energy and many others.

\section{DIRECT LASER WRITING IN GLASS AND REDISTRIBUTION OF ELEMENTS}

In addition to changing the chemical composition of glass, post-processing methods are important technologies for creating materials with specified properties. Using methods of ion exchange and surface coatings, it is possible to create highstrength and energy-efficient materials with specified optical properties. At once, the possibility of micro- and even nanoscale control of glass properties opens up previously impossible ways for the development of new materials and devices. Due to the intensive evolution of femtosecond laser technology, a wide field of research has emerged into the interaction of ultrashort laser pulses with glasses. Through a multiphoton mechanism, the energy of focused ultrashort laser pulses is absorbed by glass in the focus area. In this area, laser intensity exceeds the values of $10^{13} \mathrm{~W} / \mathrm{cm}^{2}$, resulting in modification of the glass structure. The non-linear nature of the absorption of ultrashort pulses makes it possible to control the spatial position of modified regions in the volume of glass, which opens up prospects for their threedimensional (3D) modification at the micro- and nanoscale by so-called direct laser writing (DLW) technique (Osellame et al., 2012; Sugioka and Cheng, 2014; Phillips et al., 2015).

In recent years, studies on DLW of various structures in glasses have revealed a wide range of phenomena that occur when the material absorbs ultrashort pulses. These include local changes in the refractive index and writing of optical waveguides (Phillips et al., 2015), the formation of surface and bulk birefringent nanoperiodic structures (nanogratings) (Shimotsuma et al., 2003; Lotarev et al., 2019a), formation of micro-and nanobubbles (Bellouard and Hongler, 2011), local crystallization of non-linear phases in glass (Lipatiev et al., 2018b, 2020; Lotarev et al., 2019b), precipitation of metal clusters, nanoparticles, and semiconductor quantum dots (Marquestaut et al., 2014; Shakhgildyan et al., 2018; Vetchinnikov et al., 2018; $\mathrm{Hu}$ et al., 2019). Despite the physical nature of the processes, involved in the interaction of laser pulses with glass, they lead to a local change in the chemical composition of glass by ions migrations to different areas of the laser affected zone. According to the latest studies, glass-modifier ions ( $\mathrm{Na}, \mathrm{K}, \mathrm{Mg}, \mathrm{Ca}, \mathrm{Sr}$, $\mathrm{Ba}, \mathrm{Zr}$ ) are most susceptible to migration. When observed in a plane perpendicular to the laser beam, such ions migrate to the periphery of the laser affected zone, while glass-forming ions tend to concentrate in the center (Fernandez et al., 2018; Lotarev et al., 2018). The most promising application of DLW in glasses is multidimensional optical data storage with a high capacity and almost unlimited lifetime. This method is based on the periodic nanostructures (nanogratings) laser-written in silica glass (Shimotsuma et al., 2003). Nanogratings are formed by periodic nanoporous regions interlaced with solid glass. They are oriented perpendicular to the plane of polarization of the writing beam and exhibiting form birefringence which can be used for the data encoding (Zhang et al., 2014). In order to increase data writing speed, it was proposed to use nanoporous $\mathrm{SiO}_{2}$ glass as storage media instead of silica glass (Fedotov et al., 2018; Lipatiev et al., 2018a). In this case, birefringent sub-micron hollow cavities were formed under the action of ultrafast laser pulses. The above-mentioned promising results served as the basis for launching applied research projects aimed at creating glass-based optical memory technology. The first project of this kind was launched in the Mendeleev University in Russia (Project "Quartz") Lotarev (2017), next in the Microsoft laboratories (Project "Silica”) Project Silica (2017).

Thus, using various combinations of chemical elements for glass production and laser processing methods, it is possible to create new materials and devices for a wide range of applications. First of all, they include secure data storage, as well as elements of integrated photonic circuits (waveguides, interferometers, switches), optical sensors, microfluidic devices, and much more. The processes occurring during the interaction of femtosecond laser radiation with glass, in most cases, lead to a local change in its chemical composition and migration of chemical elements to certain zones limited by the laser spot, which largely determines the changed properties of the resulting region. At the same time, the ability of a fine-tuning of glass composition at the production stage allows to ensure the most efficient flow of DLW processes.

\section{ETERNAL AND MINIATURE PERIODIC TABLE}

To symbolically mark the possibility of using almost all elements of the Periodic Table in glass, we inscribed a color image in polarized light of the Periodic Table in the volume of commercially available KU-1 type silica glass (TechnoQuartz Ltd., Russia) using the DLW method. This writing technology is based on the birefringent properties of laser-induced

TABLE 1 | Writing conditions for the DLW of the Periodic Table in the sample of silica glass.

\begin{tabular}{lccc}
\hline Group of elements & $\begin{array}{c}\text { Number } \\
\text { of layers }\end{array}$ & $\begin{array}{c}\text { Shift between } \\
\text { layers, } \boldsymbol{\mu \mathbf { m }}\end{array}$ & $\begin{array}{c}\text { Pulse energy, } \\
\boldsymbol{\mu} \mathbf{J}\end{array}$ \\
\hline Alkali and alkali earth metals & 1 & - & 4.8 \\
Transition metals & 2 & 100 & 4.2 \\
Non-metals & 3 & 130 & 4.2 \\
Lanthanides and Actinides & 2 & 175 & 4.2 \\
Post-transition metals & 2 & 290 & 4.2 \\
Noble gases & 2 & 44 & 4.2
\end{tabular}



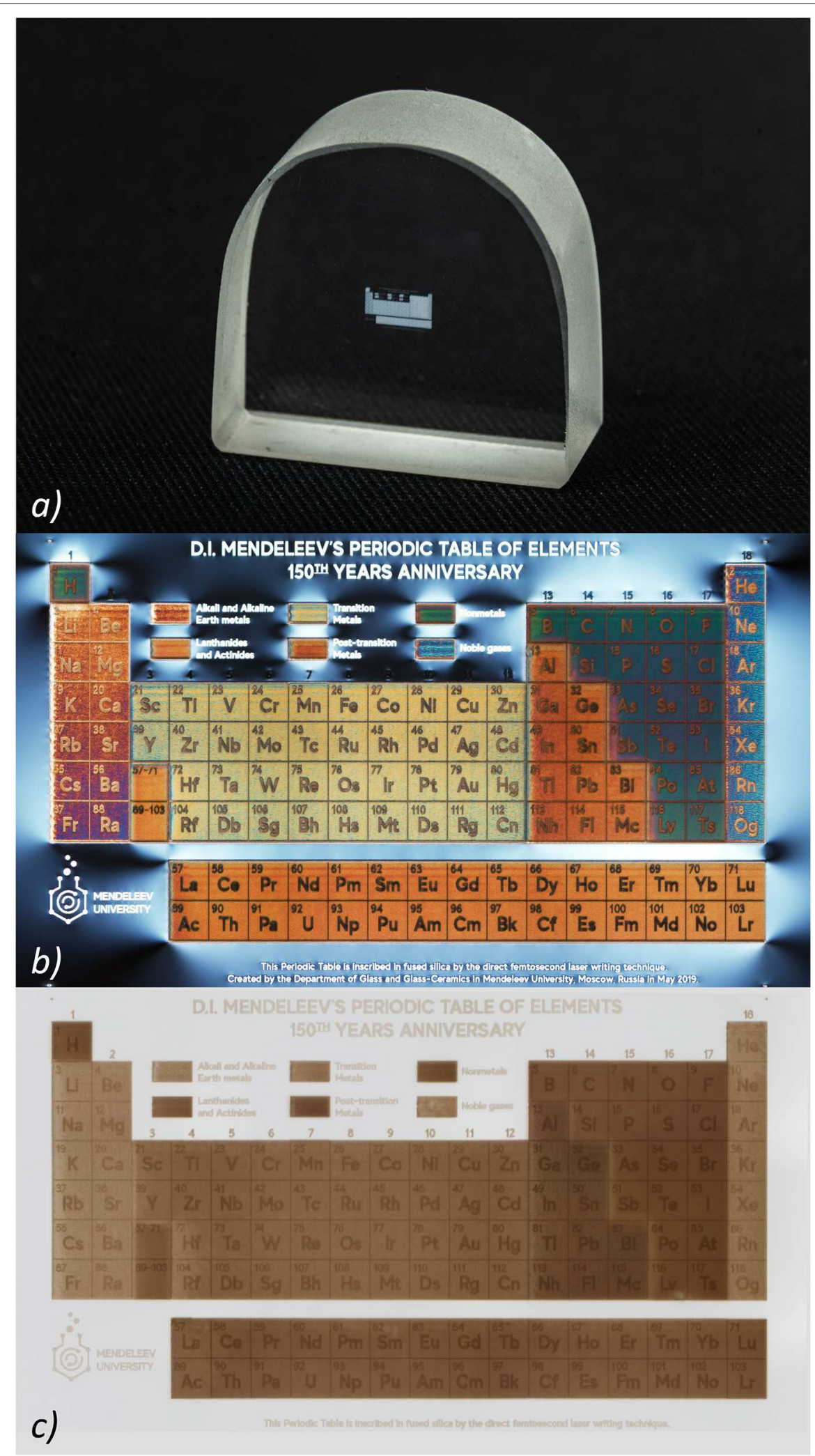

FIGURE 1 | (a) Real-size image of the silica glass sample with the laser written Periodic Table; (b,c) Optical microscopy image of the Periodic Table laser written in the silica glass sample captured with and without crossed polarizers, respectively. The length of the one cell is $200 \mu \mathrm{m}$. 
nanogratings and stress, due to which it is possible to vary the wavelength of light passing through the polarizer and light analyzer (Spring et al., 2010; Sun et al., 2020).

In this work, the Periodic Table was written in a $10 \mathrm{~mm}$ thick silica glass sample at a depth of 900 microns from the surface by a laser beam focused with a Mitutoyo MPlan APO 5X lens (N. A. = 0.14). We used Pharos $6 \mathrm{~W}$ femtosecond laser (Light Conversion Dev.) with a $1,030 \mathrm{~nm}$ central wavelength. To control the color of cells via their birefringence in the Periodic Table, the energy of laser pulses, the number of layers, and the distance between them were varied. The scanning speed of the laser beam was 2 $\mathrm{mm} / \mathrm{s}$. The writing conditions of certain groups of elements are shown in Table 1. It should be mentioned that Table 1 represents the actual interlayer shift whereas the corresponding shift of the sample during writing of the Periodic Table was equal to these values divided by 1.45 taking the refraction into account because the refractive index of silica glass is 1.45 at $1030 \mathrm{~nm}$ wavelength. The names of the elements were written using tighter focusing of the laser beam by means of an Olympus LCPLNIR 20X lens $(\mathrm{N} . \mathrm{A} .=0.45)$ and with the relative rotation of the laser beam polarization plane by $45^{\circ}$.

The photo of the glass sample with the written Table is shown in Figure 1a. The total size of the Table is $3.6 \times 2.4 \mathrm{~mm}$. To see the Table in color, it is necessary to observe it through a microscope with crossed polarizers (Figure 1b), while the image of the Table without crossed polarizers is shown in Figure 1c. The size of each Table cell is $200 \times 200$ microns. Annealing of a glass sample with a written Table at $900^{\circ} \mathrm{C}$ for $1 \mathrm{~h}$ does not lead to noticeable degradation of the image nevertheless its color was slightly changed due to the relaxation of laser-induced stress. After repeated thermal shocks (rapid cooling from $900^{\circ} \mathrm{C}$ to cold water) of the glass sample with the written Table completely retains its integrity. Due to the high chemical and radiation stability of silica glass, written image is also not subjected to degradation under the influence of moisture, acids, alkalis and radiation exposure (within the stability of silica glass). Thus, on the one hand, glass can be produced using almost all elements of the Periodic Table, and on the other, thanks to the DLW method, glass becomes the eternal storage of the Periodic Table.

\section{DISCUSSION AND CONCLUSION}

Despite the long history, today glass is the most important class of materials that is in demand in various industries. The variety of properties and applications of glass is associated with an unimaginably large number of possible

\section{REFERENCES}

Ballato, J., and Dragic, P. (2016). Glass: the carrier of light - a brief history of optical fiber. Int. J. Appl. Glass Sci. 7, 413-422. doi: 10.1111/ijag.12239

Bellouard, Y., and Hongler, M.-O. (2011). Femtosecond-laser generation of self-organized bubble patterns in fused silica. Opt. Express 19, 6807-6821. doi: $10.1364 /$ oe. 19.006807

Campbell, J. H., and Suratwala, T. I. (2000). Nd-doped phosphate glasses for high-energy/high-peak-power lasers. J. Non Cryst. Solids 263-264, 318-341. doi: 10.1016/S0022-3093(99)00645-6 compositions - combinations of various chemical elements. New opportunities for creating materials based on glass with unique properties are introduced by laser modification methods, which allow to create various multifunctional structures and objects in the glass volume.

In honor of the 150th anniversary of the Periodic Table of chemical elements, we showed the possibility of creating a color image of the Periodic Table in silica glass using direct laser writing technology. This image covers an area of $3.6 \times 2.4 \mathrm{~mm}$, while the size of each Table cell is $200 \times 200$ microns. Annealing of a glass sample with a written Table at $900^{\circ} \mathrm{C}$ for $1 \mathrm{~h}$ does not lead to noticeable degradation of the image. After repeated thermal shocks of the glass sample with the Table it completely retains its integrity. Due to the high chemical and radiation stability of silica glass, the written image is also not subjected to degradation under the influence of moisture, acids, alkalis and radiation exposure (within the stability of silica glass). Therefore, the created Table image can be considered eternal.

Thus, we want to show that on the one hand, glass can be produced using almost all elements of the Periodic Table, and on the other, that thanks to the DLW method, glass becomes the eternal storage of the Periodic Table. With these conclusions, we want to emphasize the importance of developing research in the field of glassy materials, which, thanks to the variety of elements of the Periodic Table and the use of new technologies, ensure the ever-accelerating development of the material science, instrumentation and information base of mankind.

\section{DATA AVAILABILITY STATEMENT}

The datasets generated for this study are available on request to the corresponding author.

\section{AUTHOR CONTRIBUTIONS}

GS, AL, SL, and VS contributed the conception and design of the study. Experimental work was carried out by AL and SF (programming, modeling, and laser writing) under supervision of SL and VS. GS wrote the manuscript and prepared images with contributions of AL, SL, and VS in certain sections. All authors participated in the analysis and discussion of obtained results.

\section{FUNDING}

This work was supported by the grant of Mendeleev University, Project No. 2020-020. Springer Handbook of Glass, eds J. D. Musgraves, J. Hu, L. Calvez (Springer International Publishing), 595-616. doi: 10.1007/978-3-319-93728-1_17

Ehrhardt, G. J., and Day, D. E. (1987). Therapeutic use of ${ }^{90} \mathrm{Y}$ microspheres. Int. J. Rad. Appl. Instrum. B 14, 233-242. doi: 10.1016/0883-2897(87) 90047-x

Fedotov, S. S., Okhrimchuk, A. G., Lipatiev, A. S., Stepko, A. A., Piyanzina, K. I., Shakhgildyan, G. Y., et al. (2018). 3-bit writing of information in nanoporous glass by a single sub-microsecond burst of femtosecond pulses. Opt. Lett. 43:851. doi: 10.1364/ol.43.000851 
Feller, S. (2019). "Borate glasses," in Springer Handbook of Glass, eds J. D. Musgraves, J. Hu, L. Calvez. 505-524. doi: 10.1007/978-3-319-93728-1_14

Fernandez, T. T., Sakakura, M., Eaton, S. M., Sotillo, B., Siegel, J., Solis, J., et al. (2018). Bespoke photonic devices using ultrafast laser driven ion migration in glasses. Progr. Mater. Sci. 94, 68-113. doi: 10.1016/j.pmatsci.2017.12.002

Gin, S., Abdelouas, A., Criscenti, L. J., Ebert, W. L., Ferrand, K., Geisler, T., et al. (2013). An international initiative on long-term behavior of high-level nuclear waste glass. Mater. Today 16, 243-248. doi: 10.1016/j.mattod.2013.06.008

Greer, A. L. (1995). Metallic glasses. Science 267, 1947-1953. doi: $10.1126 /$ science. 267.5206 .1947

Hu, Y., Zhang, W., Ye, Y., Zhao, Z., and Liu, C. (2019). Femtosecond-laser-induced precipitation of $\mathrm{CsPbBr} 3$ perovskite nanocrystals in glasses for solar spectral conversion. ACS Appl. Nano Mater. 3, 850-857. doi: 10.1021/acsanm.9b02362

Hubert, M., Delaizir, G., Monnier, J., Godart, C., Ma, H. L., Zhang, X. H., et al. (2011). An innovative approach to develop highly performant chalcogenide glasses and glass-ceramics transparent in the infrared range. Opticsexpress 19, 23513-23522. doi: 10.1364/OE.19.023513

LeLosq, C., Cicconi, M. R., Greaves, G. N., and Neuville, D. R. (2019). "Silicate glasses," in Springer Handbook of Glass, eds J. D. Musgraves, J. Hu, L. Calvez. 441-503. doi: 10.1007/978-3-319-93728-1_13

Lipatiev, A. S., Fedotov, S. S., Okhrimchuk, A. G., Lotarev, S. V., Vasetsky, A. M., Stepko, A. A., et al. (2018a). Multilevel data writing in nanoporous glass by a few femtosecond laser pulses. Appl. Opt. 57, 978-982. doi: 10.1364/ao.57.000978

Lipatiev, A. S., Lotarev, S. V., Smayev, M. P., Lipateva, T. O., Karateev, I. A., Presnyakov, M. Y., et al. (2020). Space-selective crystallization of glass by an optical vortex beam. CrystEngComm 22, 430-434. doi: 10.1039/c9ce01869g

Lipatiev, A. S., Moiseev, I. A., Lotarev, S. V., Lipateva, T. O., Presnyakov, M. Y., Fedotov, S. S., et al. (2018b). Growth of fresnoite single crystal tracks inside glass using femtosecond laser beam followed by heat treatment. Cryst. Growth Des. 18, 7183-7190. doi: 10.1021/acs.cgd.8b01358

Lorenzi, R., Golubev, N. V., Ziaytdinova, M. Z., Jar,ý, V., Babin, V., Malashkevich, G. E., et al. (2018). Radio- and photoluminescence properties of $\mathrm{Ce} / \mathrm{Tb}$ co-doped glasses with huntite-like composition. Opt. Mater. 78, 247-252. doi: 10.1016/j.optmat.2018.02.016

Lotarev, S. (2017). In Search of Permanent Memory: From Cuneiform on Clay to Nanostructures in Glass.Available online at: https://www.kommersant. uk/articles/in-search-of-permanent-memory-from-cuneiform-on-clay-tonanostructures-in-glass (accessed March 15, 2020).

Lotarev, S., Fedotov, S., Lipatiev, A., Presnyakov, M., Kazansky, P., and Sigaev, V. (2018). Light-driven nanoperiodical modulation of alkaline cation distribution inside sodium silicate glass. J. Non Cryst. Solids 479, 49-54. doi: 10.1016/j.jnoncrysol.2017.10.008

Lotarev, S. V., Fedotov, S. S., Kurina, A. I., Lipatiev, A. S., and Sigaev, V. N. (2019a). Ultrafast laser-induced nanogratings in sodium germanate glasses. Opt. Lett. 44, 1564-1567. doi: 10.1364/ol.44.001564

Lotarev, S. V., Lipatiev, A. S., Lipateva, T. O., Fedotov, S. S., Naumov, A. S., Moiseev, I. A., et al. (2019b). Ultrafast-laser vitrification of laserwritten crystalline tracks in oxide glasses. J. Non Cryst. Solids 516, 1-8. doi: 10.1016/j.jnoncrysol.2019.04.027

Marquestaut, N., Petit, Y., Royon, A., Mounaix, P., Cardinal, T., and Canioni, L. (2014). Three-dimensional silver nanoparticle formation using femtosecond laser irradiation in phosphate glasses: analogy with photography. Adv. Funct. Mater. 24, 5824-5832. doi: 10.1002/adfm.201401103

Mauro, J. C., and Morten, M. S. (2014). Ultra-Thin Strengthened Glasses. U.S. Patent Application No. 13/961, 211.

Mendeleev, D. I. (1864). Glass Production. Saint Petersburg: Public benefit.

Muñoz, F., Rocherullé, J., Ahmed, I., and Hu, L. (2019). "Phosphate glasses," in Springer Handbook of Glass, eds J. D. Musgraves, J. Hu, L. Calvez. 553-594. doi: 10.1007/978-3-319-93 728-1_16

Osellame, R., Cerullo, G., and Ramponi, R. (Eds.). (2012). "Femtosecond laser micromachining," in Topics in Applied Physics (Berlin; Heidelberg: Springer). doi: 10.1007/978-3-642-23366-1

Phillips, K. C., Gandhi, H. H., Mazur, E., and Sundaram, S. K. (2015). Ultrafast laser processing of materials: a review. Adv. Opt. Photonics 7:684. doi: 10.1364/aop.7.000684

Project Silica, (2017). Microsoft Research. Available online at: https://www. microsoft.com/en-us/research/project/project-silica/c (accessed March 15, 2020).
Rezaei, S. D., Shannigrahi, S., and Ramakrishna, S. (2017). A review of conventional, advanced, and smart glazing technologies and materials for improving indoor environment. Solar Energy Mater. Solar Cells 159, 26-51. doi: 10.1016/j.solmat.2016.08.026

Schroers, J. (2013). Bulk metallic glasses. Phys. Today 66, 32-37. doi: $10.1063 /$ pt.3.1885

Shakhgildyan, G. Y., Lipatiev, A. S., Vetchinnikov, M. P., Popova, V. V., Lotarev, S. V., Golubev, N. V., et al. (2018). One-step micro-modification of optical properties in silver-doped zinc phosphate glasses by femtosecond direct laser writing. J. Non Cryst. Solids 481, 634-642. doi: 10.1016/j.jnoncrysol.2017.12.011

Shimotsuma, Y., Kazansky, P. G., Qiu, J., and Hirao, K. (2003). Self-organized nanogratings in glass irradiated by ultrashort light pulses. Phys. Rev. Lett. 91:247405. doi: 10.1103/physrevlett.91.247405

Sigaev, V. N., Atroschenko, G. N., Savinkov, V. I., Sarkisova, P. D., Babajewb, G., Lingel, K., et al. (2012). Structural rearrangement at the yttrium-depleted surface of $\mathrm{HCl}$-processed yttrium aluminosilicate glass for ${ }^{90}$ Y-microsphere brachytherapy. Mater. Chem. Phys. 133, 24-28. doi: 10.1016/j.matchemphys. 2011.12.079

Sigaev, V. N., Golubev, N. V., Ignat'eva, E. S., Savinkov, V. I., Campione, M., Lorenzi, R., et al. (2011). Nickel-assisted growth and selective doping of spinel-like gallium oxide nanocrystals in germano-silicate glasses for infrared broadband light emission. Nanotechnology 23:15708. doi: 10.1088/0957-4484/23/1/015708

Spring, K. R., Parry-Hill, M. J., and Davidson, M. W. (2010). Michel-Levy Birefringence Chart. Olympus Microscopy Resource Center. Available online at: http://olympus.magnet.fsu.edu/primer/java/polarizedlight/michellevy/ index.html

Starobor, A. V., Zheleznov, D. S., Palashov, O. V., Savinkov, V. I., and Sigaev, V. N. (2016). Borogermanate glasses for Faraday isolators at high average power. Opt. Commun. 358, 176-179. doi: 10.1016/j.optcom.2015.09.047

Starodubov, D., Mechery, S., Miller, D., Ulmer, C., Willems, P., Ganley, J., et al. (2014). ZBLAN fibers: from zero gravity tests to orbital manufacturing. Appl. Ind. Optics. doi: 10.1364/aio.2014.am4a.2

Strahan, D. (2001). Uranium in glass, glazes and enamels: history, identification and handling. Stud. Conserv. 46, 181-195. doi: 10.1179/sic.2001.4 6.3 .181

Sugioka, K., and Cheng, Y. (2014). Ultrafast lasers-reliable tools for advanced materials processing. Light Sci. Appl. 3:e149. doi: 10.1038/lsa.2014.30

Sun, Q., Lee, T., Beresna, M., and Brambilla, G. (2020). Control of laser induced cumulative stress for efficient processing of fused silica. Sci. Rep. 10:3819. doi: 10.1038/s41598-020-60828-3

Vetchinnikov, M. P., Lipatiev, A. S., Shakhgildyan, G. Y., Golubev, N. V., Ignat'eva, E. S., Fedotov, S. S., et al. (2018). Direct femtosecond laser-induced formation of CdS quantum dots inside silicate glass. Opt. Lett. 43, 2519-2522. doi: 10.1364/ol.43.002519

Wetenkamp, L., West, G. F., and Többen, H. (1992). Optical properties of rare earth-doped ZBLAN glasses. J. Non Cryst. Solids 140, 35-40. doi: 10.1016/s0022-3093(05)80737-9

Zanotto, E. D. (2010). Bright future for glass-ceramics. Am. Ceramics Soc. Bull. 89, 19-27.

Zanotto, E. D., and Coutinho, F. A. B. (2004). How many non-crystalline solids can be made from all the elements of the periodic table? J. Non Cryst. Solids 347, 285-288. doi: 10.1016/j.jnoncrysol.2004.07.081

Zhang, J., Gecevičius, M., Beresna, M., and Kazansky, P. G. (2014). Seemingly unlimited lifetime data storage in nanostructured glass. Phys. Rev. Lett. 112:033901. doi: 10.1103/PhysRevLett.112.0 33901

Conflict of Interest: The authors declare that the research was conducted in the absence of any commercial or financial relationships that could be construed as a potential conflict of interest.

Copyright (c) 2020 Shakhgildyan, Lipatiev, Lotarev, Fedotov and Sigaev. This is an open-access article distributed under the terms of the Creative Commons Attribution License (CC BY). The use, distribution or reproduction in other forums is permitted, provided the original author(s) and the copyright owner(s) are credited and that the original publication in this journal is cited, in accordance with accepted academic practice. No use, distribution or reproduction is permitted which does not comply with these terms. 